\title{
Physical inactivity and arterial stiffness in COPD
}

This article was published in the following Dove Press journal: International Journal of COPD

10 September 2015

Number of times this article has been viewed

\author{
Noriane A Sievi' \\ Daniel Franzen' \\ Malcolm Kohler ${ }^{1,2}$ \\ Christian F Clarenbach' \\ 'Division of Pulmonology, University \\ Hospital of Zurich, ${ }^{2}$ Zurich Center \\ for Integrative Human Physiology, \\ University of Zurich, Zurich, \\ Switzerland
}

Background: Arterial stiffness is an important predictor of cardiovascular risk besides classic cardiovascular risk factors. Previous studies showed that arterial stiffness is increased in patients with COPD compared to healthy controls and exercise training may reduce arterial stiffness. Since physical inactivity is frequently observed in patients with COPD and exercise training may improve arterial stiffness, we hypothesized that low daily physical activity may be associated with increased arterial stiffness.

Methods: In 123 patients with COPD (72\% men; mean [standard deviation] age: 62 [7.5] years; median [quartile] forced expiratory volume in 1 second 35 [27/65] \%predicted), arterial stiffness was assessed by augmentation index (AI). Daily physical activity level (PAL) was measured by an activity monitor (SenseWear Pro $^{\mathrm{TM}}$ ) $>1$ week. The association between AI and PAL was investigated by univariate and multivariate regression analysis, taking into account diseasespecific characteristics and comorbidities.

Results: Patients suffered from moderate (35\%), severe (32\%), and very severe (33\%) COPD, and 22\% were active smokers. Median (quartile) PAL was $1.4(1.3 / 1.5)$ and mean (standard deviation) AI 26\% (9.2\%). PAL showed a negative association with AI ( $B=-9.32, P=0.017)$ independent of age, sex, blood pressure, and airflow limitation.

Conclusion: In COPD patients, a higher PAL seems to favorably influence arterial stiffness and therefore may reduce cardiovascular risk.

Clinical Trial Registration: www.ClinicalTrials.gov, NCT01527773

Keywords: activity monitor, airflow limitation, COPD, physical activity level

\section{Introduction}

COPD is associated with an increased risk of cardiovascular morbidity and mortality. ${ }^{1-3}$ Vascular dysfunction may represent a mechanism through which COPD leads to cardiovascular disease. Arterial stiffness is increased even in early stages of atherosclerosis and thus may be helpful in identifying patients at increased vascular risk. ${ }^{4}$ Pulse wave analysis-derived measures of arterial stiffness such as pulse wave velocity (PWV) and augmentation index (AI) have been shown to independently predict cardiovascular risk and mortality. ${ }^{5-7}$ In COPD patients, arterial stiffness assessed by PWV and AI has been shown to be elevated compared to healthy controls. ${ }^{8,9}$ Previous studies in COPD patients showed incongruent results regarding the association between arterial stiffness, airflow limitation, ${ }^{9,10}$ and systemic inflammation. ${ }^{9,11}$ A recent summary on arterial stiffness in COPD postulated that these processes may lead to vascular remodeling and atherosclerosis progression finally leading to cardiovascular events. ${ }^{12}$ Physical inactivity is associated with a higher risk for cardiovascular disease in the general population. ${ }^{13}$ Physical activity (PA) represents any bodily movement produced by skeletal muscles that results in energy expenditure and received more attention in COPD-related research in recent years. Most patients with COPD present with remarkably low levels of PA compared to subjects without COPD, even in mild to moderate stages of the disease. ${ }^{14}$ In longitudinal cohort studies, regular PA has been shown to
Correspondence: Christian F Clarenbach Division of Pulmonology, University Hospital of Zurich, Raemistrasse I00, 8091 Zurich, Switzerland

$\mathrm{Tel}+4 \mid 442553828$

Fax +4I 44255445 I

Email christian.clarenbach@usz.ch 
reduce hospital admission and mortality in COPD patients. ${ }^{15}$ In a previous study evaluating endothelial function in COPD patients, we found that PA showed a positive independent effect on endothelial function. ${ }^{3}$ Therefore, the level of daily PA may be an important determinant of vascular damage in patients with COPD. However, endothelial dysfunction and arterial stiffness represent two different aspects of vascular health. While arterial stiffness is determined mainly by the elastin to collagen ratio in the arterial wall, the endothelium senses change in hemodynamic signals and respond by release of relaxing factors including nitric oxide that plays a key role in maintaining vascular homeostasis. ${ }^{16}$ Therefore, we hypothesized that a lower level of daily PA is associated with increased arterial stiffness in a heterogeneous group of COPD patients.

\section{Methods}

\section{Subjects}

This study was performed as a substudy of The Obstructive Pulmonary Disease Outcomes Cohort of Switzerland (TOPDOCS). TOPDOCS is an ongoing prospective, noninterventional cohort study. Patients were recruited during ambulatory visits in the pulmonary clinics or during hospital stay. Patients aged between 40 years and 75 years with objectively confirmed COPD according to GOLD guidelines ${ }^{17}$ were assessed for eligibility between October 2011 and September 2014. Patients were excluded if they had suffered from a COPD exacerbation within the last 6 weeks or if they suffered from mental or physical disability precluding informed consent or compliance with the protocol.

The study was conducted in accordance with the Declaration of Helsinki of the World Medical Association. The Ethics Committee of the Canton of Zurich approved the study (EK-ZH-NR: 2011-0106), and the study was registered at www.ClinicalTrials.gov, NCT01527773. All subjects gave written informed consent to participate.

\section{Measurements}

\section{Arterial stiffness}

After resting 10 minutes in supine position, radial artery pulse waveforms were recorded with a pressure tonometer (SphygmoCor System; AtCor Medical, Sydney, NSW, Australia). Approximately ten radial pulse waves were measured to generate a corresponding central aortic pressure waveform with a validated mathematical transfer function. ${ }^{18}$ With an algorithm, the inflection point of the aortic pressure waveform can be determined, which corresponds to the onset of the reflected wave returning from peripheral arteries and divides the aortic pressure wave into an early and late systolic peak. AI as a measure for peripheral arterial wave reflection quantifies augmentation of central aortic pressure and is calculated as the difference between the second (P2) and first (P1) systolic peak pressure and is expressed as percentage of the central pulse pressure $(\mathrm{PP})$ : $\mathrm{AI}(\%)=[(\mathrm{P} 2-\mathrm{P} 1) / \mathrm{PP}] \times 100$ (Figure 1). AI is corrected to a heart rate of $75 \mathrm{bpm}$ since AI is influenced by heart rate. ${ }^{19}$ The faster the pulse wave returns from the periphery, the stiffer the arteries are and the higher the AI. Following the recommendations of the manufacturer, a measurement was only accepted when the operator index (with a range from 0 to 100 with increasing quality) was $>80$.

\section{Physical activity}

Physical activity level (PAL) and the number of steps per day were assessed by a multisensory band (SenseWear Pro ${ }^{\text {TM}}$; Bodymedia Inc., Pittsburgh, PA, USA), which was worn on the upper left arm over the triceps muscle. The SenseWear armband has been validated to be a stable measure of walking and daily PA in patients with COPD. ${ }^{20}$ Patient's data were recorded $>7$ consecutive days. The threshold for valid data from the armband was set at 4 days with a minimum of 22.5 hours/day. PAL is an objective measure of daily PA and is defined as the total energy expenditure divided by the resting metabolic rate. ${ }^{14}$ A PAL of $\geq 1.70$ defines an active person, a PAL between 1.40 and 1.69 a sedentary person, and $<1.40$ defines a very inactive person. ${ }^{14,21}$ The number of steps per day was recorded by an inbuilt biaxial accelerometer. ${ }^{22}$

\section{Lung function}

All participants underwent standard pulmonary functional testing according to American Thoracic Society guidelines

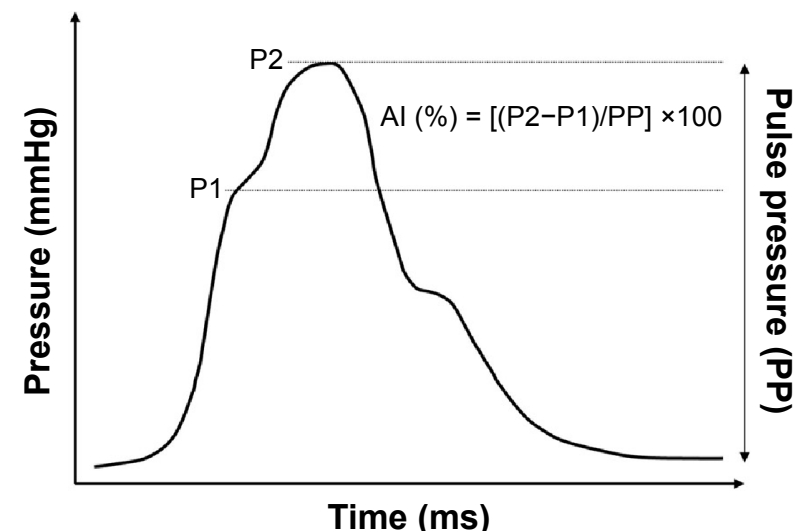

Figure I The augmentation index (AI) is calculated as the difference between the second $(\mathrm{P} 2)$ and first $(\mathrm{PI})$ systolic peak pressure and is expressed as percentage of the central PP: $\mathrm{Al}(\%)=[(\mathrm{P} 2-\mathrm{PI}) / \mathrm{PP}] \times 100$. 
to measure forced expiratory volume in 1 second $\left(\mathrm{FEV}_{1}\right)$, forced vital capacity, ${ }^{23}$ diffusion capacity (TLco), residual volume (RV), total lung capacity (TLC), and hyperinflation (RV/TLC). ${ }^{24}$ Values after bronchodilatation are reported.

\section{Data analysis and statistics}

All results are shown as mean (standard deviation [SD]) and median (quartiles) unless otherwise stated. Statistical analysis was performed with STATA 13 (StataCorp LP, College Station, TX, USA).

Univariate regression analysis was used to investigate associations between $\mathrm{AI}$ (dependent variable) and PAL as well as possible predictors for AI, such as age, sex, body mass index (BMI), smoking, blood pressure, lung function, cardiovascular comorbidities, and c-reactive protein. To further investigate the independent association between $\mathrm{AI}$ and PAL, multivariate analysis involved regression of variables that showed a univariate regression $P$-value of $<0.1$. To take into account a nonlinear association between $\mathrm{AI}$ and age, the squared term of age (age $\times$ age) was included in the analysis. Residual analysis of the model was performed to check the regression assumptions. A two-sided $P$-value of $<0.05$ was considered to be statistically significant.

\section{Results}

\section{Study participants and baseline characteristics}

A total of 123 COPD patients entered the final analysis (Figure 2). Of those patients, 35\% were classified as GOLD $1 / 2,32 \%$ GOLD 3 , and 33\% GOLD 4 . According to the novel GOLD classification (www.goldcopd.org) considering symptoms and exacerbations, $11 \%$ were classified as risk group A, $24 \%$ group B, $4 \%$ group C, and $61 \%$ group D. The mean (SD) age was $62(7.5)$ years. Sixty-six percent of the patients had a known cardiovascular comorbidity. Seventyfive percent of the patients used long-acting bronchodilators,

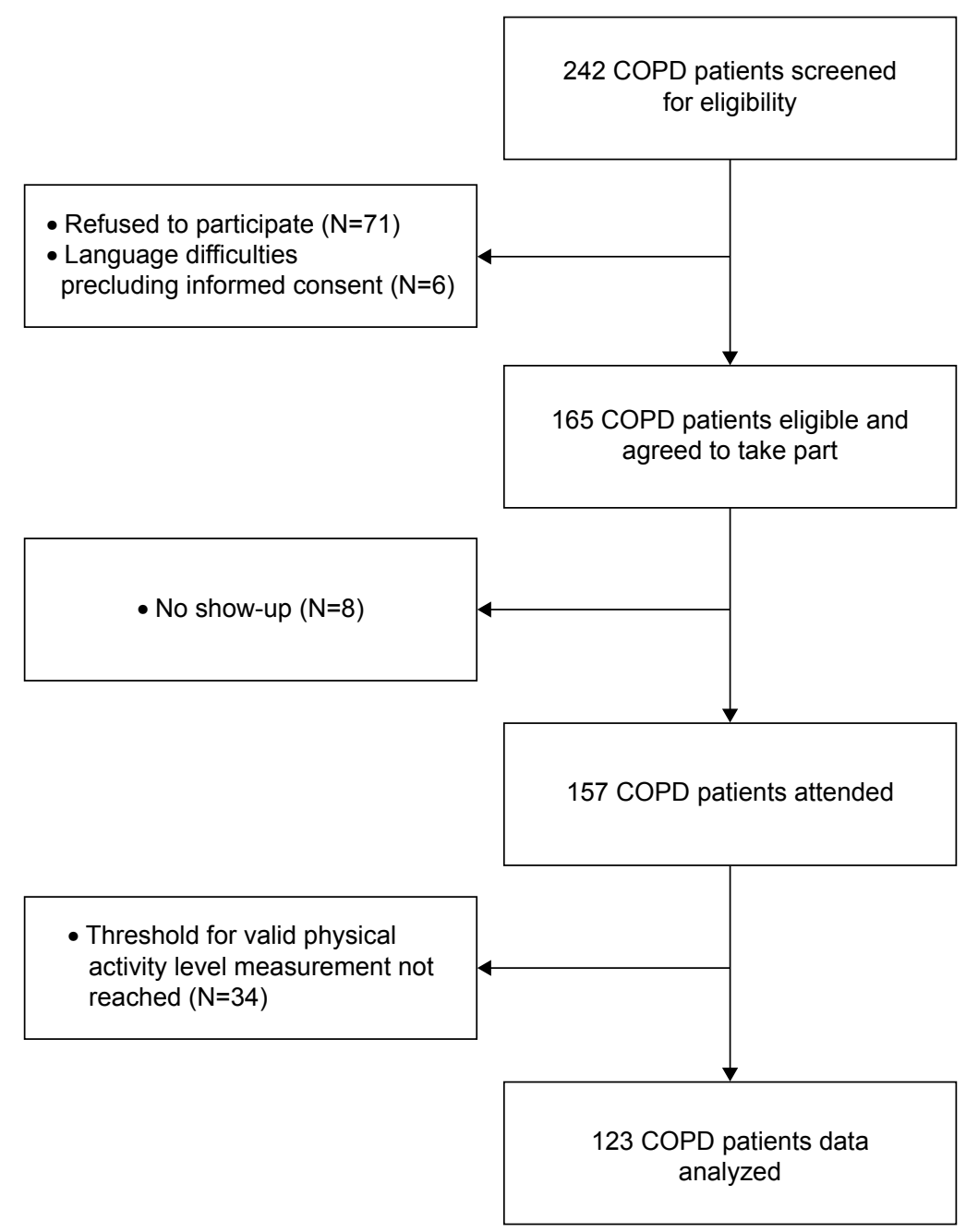

Figure 2 Study flow. 
and $56 \%$ also inhaled a corticosteroid on a regular base. Blood pressure-lowering medications were taken by $53 \%$ of the patients, and $36 \%$ used lipid-lowering medications. Median (quartile) PAL was 1.4 (1.3/1.5) and mean (SD) AI $26 \%(9.2 \%)$. The detailed patient characteristics are shown in Table 1.

\section{Predictors of $\mathrm{Al}$}

AI was negatively associated with sex, BMI, and PAL. Systolic blood pressure, diastolic blood pressure, and age (nonlinear) were positively associated with AI in univariate regression (Table 2). Table 3 shows the independent determinants of AI based on the multiple regression analysis. PAL, male sex, and BMI were negatively associated with AI. Furthermore, a nonlinear positive association between $\mathrm{AI}$ and age and a linear positive association between systolic blood pressure and AI were observed. Airflow limitation was not independently associated with AI. Due to a high

Table I Patient characteristics

\begin{tabular}{|c|c|}
\hline Age, y & $62(7.5)$ \\
\hline Male/female & $89 / 35$ \\
\hline BMI, $\mathrm{kg} / \mathrm{m}^{2}$ & $24.9(22.4 / 28.4)$ \\
\hline Current smoker, N (\%) & $27(22)$ \\
\hline Pack years of smoking, $\mathrm{N}$ & $39(26.5 / 60.0)$ \\
\hline Systolic BP, mmHg & $129(15.8)$ \\
\hline Diastolic BP, mmHg & $81(10.1)$ \\
\hline $\mathrm{FEV}_{1}$, \%predicted & $35(27.0 / 65.0)$ \\
\hline FVC, \%predicted & $79(18.6)$ \\
\hline RV, \%predicted & $179(\mid 25.0 / 225.0)$ \\
\hline TLC, \%predicted & $115(24.0)$ \\
\hline $\mathrm{RV} / \mathrm{TLC}$ & $56(13.0)$ \\
\hline TLco, \%predicted & $36(15.0 / 55.0)$ \\
\hline Antihypertensivum, N (\%) & $65(53)$ \\
\hline Statin, N (\%) & $44(36)$ \\
\hline LAMA only, N (\%) & $8(7)$ \\
\hline LAMA + GC, N (\%) & $2(2)$ \\
\hline LABA only, $N(\%)$ & $5(4)$ \\
\hline LABA + GC, N (\%) & $13(11)$ \\
\hline LAMA + LABA, N (\%) & $5(4)$ \\
\hline LAMA + LABA + GC, N (\%) & $69(56)$ \\
\hline Arterial hypertension, $\mathrm{N}(\%)$ & $54(44)$ \\
\hline CVD, N (\%) & $27(22)$ \\
\hline PAD, N (\%) & $12(10)$ \\
\hline CRP, mg/L & $1.8(0.9 / 4.0)$ \\
\hline PAL & $1.4(1.3 / 1.5)$ \\
\hline Number of steps per day, $\mathrm{N}$ & $4,149(2,498.5 / 6,679.0)$ \\
\hline Augmentation index, $\%$ & $26(9.2)$ \\
\hline
\end{tabular}

Note: Values are median (quartiles) or mean (SD) unless otherwise stated. Abbreviations: $y$, years; BMI, body mass index; BP, blood pressure; $\mathrm{FEV}_{1}$, forced expiratory volume in I second; FVC, forced volume capacity; RV, residual volume; TLC, total lung capacity; TLco, diffusion capacity; LAMA, long-acting muscarinic antagonist; LABA, long-acting beta-agonist; GC, glucocorticoids; CVD, cardiovascular disease; PAD, peripheral artery disease; CRP, c-reactive protein; PAL, physical activity level.
Table 2 Univariate regression analysis of possible predictors for aortic augmentation index

\begin{tabular}{|c|c|c|c|}
\hline & B & $\begin{array}{l}95 \% \text { confidence } \\
\text { interval }\end{array}$ & $P$-value \\
\hline \multicolumn{4}{|l|}{ Linear age } \\
\hline Age, y & 0.08 & $-0.14 / 0.30$ & 0.452 \\
\hline \multicolumn{4}{|l|}{ Nonlinear age } \\
\hline Age, y & 3.77 & $0.88 / 6.67$ & $0.011 *$ \\
\hline $\begin{array}{l}\text { Age } \times \text { age, } \\
\text { y (squared term) }\end{array}$ & -0.03 & $-0.05 /-0.01$ & $0.013 *$ \\
\hline Male & -7.12 & $-10.59 /-3.64$ & $<0.001 *$ \\
\hline BMI, kg/m² & -0.44 & $-0.7 \mid /-0.17$ & $0.002 *$ \\
\hline $\begin{array}{l}\text { Current } \\
\text { smoker, N }\end{array}$ & -0.05 & $-4.06 / 3.95$ & 0.979 \\
\hline $\begin{array}{l}\text { Pack years of } \\
\text { smoking, N }\end{array}$ & 0.39 & $-0.03 / 0.11$ & 0.291 \\
\hline $\begin{array}{l}\text { Systolic blood } \\
\text { pressure, } \mathrm{mmHg}\end{array}$ & 0.16 & $0.06 / 0.26$ & $0.003 *$ \\
\hline $\begin{array}{l}\text { Diastolic blood } \\
\text { pressure, } \mathrm{mmHg}\end{array}$ & 0.33 & $0.17 / 0.48$ & $<0.00 I^{*}$ \\
\hline $\mathrm{FEV}_{1}, \%$ predicted & -0.06 & $-0.14 / 0.01$ & 0.089 \\
\hline FVC, \%predicted & -0.01 & $-0.10 / 0.07$ & 0.772 \\
\hline RV/TLC, \% & 0.10 & $-0.02 / 0.23$ & 0.098 \\
\hline $\begin{array}{l}\text { Arterial } \\
\text { hypertension, } \mathrm{N}\end{array}$ & -1.56 & $-4.89 / 1.77$ & 0.355 \\
\hline CVD, $\mathrm{N}$ & -2.33 & $-6.31 / 1.65$ & 0.249 \\
\hline PAD, N & -0.06 & $-5.64 / 5.53$ & 0.984 \\
\hline $\mathrm{CRP}, \mathrm{mg} / \mathrm{L}$ & 0.03 & $-1.14 / 0.21$ & 0.699 \\
\hline PAL & -11.72 & $-19.66 /-3.78$ & $0.004 *$ \\
\hline $\begin{array}{l}\text { Number of } \\
\text { steps per day, N }\end{array}$ & -0.00 & $-0.00 / 0.00$ & 0.502 \\
\hline
\end{tabular}

interrelationship between $\mathrm{FEV}_{1}$ \%predicted and RV/TLC $(r=-0.81, P<0.001), \mathrm{FEV}_{1}$ \%predicted and TLco $(r=0.48$, $P<0.001)$, and systolic and diastolic blood pressure $(r=0.76$, $P<0.001$ ), respectively, RV/TLC, TLco, and diastolic blood pressure were removed from the model. Residual analysis of the final model did not show a violation of the regression assumptions. Multivariate regression of adjusted $\mathrm{AI}$ and $\mathrm{PAL}$ is displayed in Figure 3.

\section{Discussion}

This study investigated the impact of objectively measured PA on arterial stiffness in a heterogeneous group of COPD patients. The main finding of this study was that a lower PAL is an important determinant of arterial stiffness independent of other known confounders, such as age, sex, and systolic blood pressure. Airflow limitation was not independently associated with arterial stiffness. 
Table 3 Multiple regression analysis of possible predictors for aortic augmentation index

\begin{tabular}{|c|c|c|c|}
\hline & B & $\begin{array}{l}95 \% \text { confidence } \\
\text { interval }\end{array}$ & $P$-value \\
\hline \multicolumn{4}{|l|}{ Nonlinear age } \\
\hline Age, $y$ & 2.74 & $0.10 / 5.38$ & $0.042^{*}$ \\
\hline $\begin{array}{l}\text { Age } \times \text { age, } \\
\text { y (squared term) }\end{array}$ & -0.02 & $-0.04 /-0.00$ & $0.044^{*}$ \\
\hline Male/female & -6.64 & $-9.9 /-3.4$ & $<0.00 I^{*}$ \\
\hline $\mathrm{BMI}, \mathrm{kg} / \mathrm{m}^{2}$ & -0.35 & $-0.62 /-0.08$ & $0.012^{*}$ \\
\hline $\begin{array}{l}\text { Systolic blood } \\
\text { pressure, } \mathrm{mmHg}\end{array}$ & 0.19 & $0.10 / 0.29$ & $<0.00 I^{*}$ \\
\hline $\mathrm{FEV}_{1}, \%$ predicted & 0.03 & $-0.05 / 0.10$ & 0.474 \\
\hline PAL & -9.32 & $-16.96 /-1.68$ & $0.017^{*}$ \\
\hline
\end{tabular}

Note: $* P<0.05$.

Abbreviations: $y$, years; BMI, body mass index; $\mathrm{FEV}_{1}$, forced expiratory volume in I second; PAL, physical activity level.

Pulse wave analysis-derived measures of arterial stiffness (PWV and AI) have been shown to predict cardiovascular risk and mortality besides classic cardiovascular risk factors ${ }^{6,7,25}$ and are elevated in COPD patients. ${ }^{8,9}$ In a case-control study with 102 COPD patients and 103 healthy controls, arterial stiffness was significantly higher in the COPD group compared to controls matched for age and smoking status. ${ }^{26}$ Previous studies investigated possible predictors of arterial stiffness that typically exists in COPD patients such as airflow limitation ${ }^{9,10,27}$ and systemic inflammation. ${ }^{9,27}$ Sabit et al $^{9}$ found no association between $\mathrm{AI}$ and $\mathrm{FEV}_{1}$ in 75 stable COPD patients. Accordingly, Bhatt et $\mathrm{al}^{27}$ showed no significant differences in $\mathrm{FEV}_{1}$ \%predicted across PWV quartiles in 153 patients with

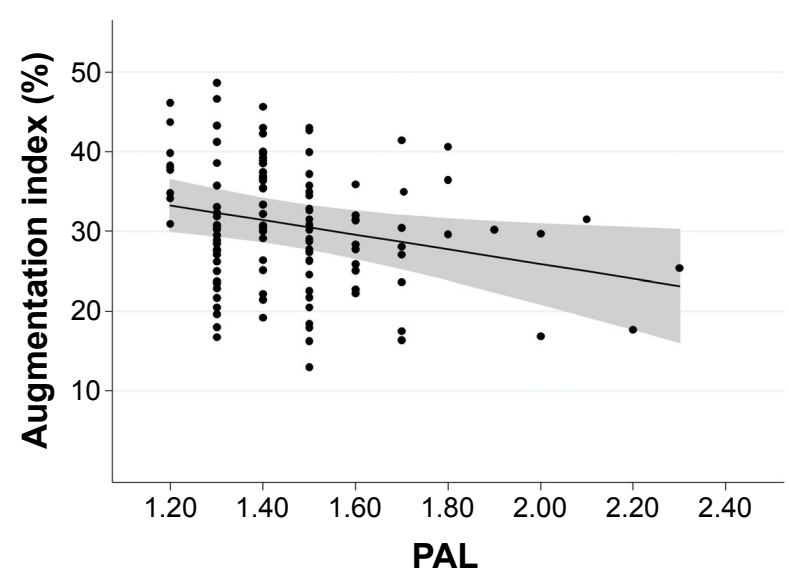

Figure $3 \mathrm{~A}$ scatterplot of $\mathrm{Al}$ and PAL adjusted for age, age $\times$ age (squared term), sex, BMI, systolic blood pressure, and FEV, \%predicted according to the final regression model is shown.

Notes: The regression line (black line) and confidence intervals (gray bar) are marked. The figure illustrates a decrease of the Al with increasing PAL in COPD patients. Abbreviations: Al, augmentation index; PAL, physical activity level; BMI, body mass index; $\mathrm{FEV}_{1}$, forced expiratory volume in I second.
COPD. In contrast, McAllister et $\mathrm{a}^{10}$ showed that PWV was higher in severe and very severe COPD patients than in those with mild to moderate COPD. Therefore, the influence of airflow limitation on arterial stiffness is still unclear due to the conflicting findings. Results from studies investigating systemic inflammation as another possible predictor for arterial stiffness in COPD patients have led to conflicting results. Systemic inflammation as an extra-pulmonary effect of COPD has been shown to increase the cardiovascular risk in COPD patients. ${ }^{28}$ In healthy individuals, arterial stiffness has been positively associated with different markers of systemic inflammation. ${ }^{29}$ In a COPD study evaluating the association between increased arterial stiffness and systemic inflammation, increased interleukin- 6 was a predictor for arterial stiffness. ${ }^{9}$ However, there are other studies indicating no effect of systemic inflammation on arterial stiffness in COPD patients. ${ }^{11}$ In our study, c-reactive protein as a marker for systemic inflammation showed also no association with arterial stiffness. The ECLIPSE study showed that systemic inflammation was present only in a $16 \%$ of the COPD patients..$^{30}$ To further address this question, it would be helpful to study exclusively the subgroup of COPD patients with persistently elevated inflammatory biomarker levels who may constitute a distinct phenotype.

Physical inactivity is a characteristic feature of COPD patients. ${ }^{14} \mathrm{~A}$ lower level of PA is known to be a strong predictor for all-cause mortality in patients with COPD. ${ }^{31}$ Previous studies in healthy individuals indicated that individuals with a higher PAL had lower arterial stiffness compared to individuals with a lower PAL. ${ }^{32,33}$ In COPD patients, there is only one study investigating the relationship between PA and arterial stiffness. Stickland et $\mathrm{l}^{34}$ investigated the association between PWV and PA and exercise intolerance, in a study with 33 COPD patients without known cardiovascular risk factors. Arterial stiffness was significantly higher in the inactive COPD group as compared to the active group, whereas daily PA was not independently associated with PWV. In contrast, we found an independent association between arterial stiffness and PAL. Our results showed that an increase in PAL of 0.2 will lead to a decrease in AI of $4 \%$, which may correspond to a decrease in cardiovascular event rate of $13 \%$ based on studies evaluating $\mathrm{AI}$ as a predictor for cardiovascular risk. ${ }^{35}$ These conflicting findings might be due to the larger sample size in our study and the different patient characteristics. Whereas we included all COPD patients to obtain a clinically representative cohort, Stickland et $\mathrm{al}^{34}$ excluded patients with known cardiovascular disease, diabetes, vasoactive medications, obesity, and 
severe inflammatory disorders. To date, there are only two studies investigating the effect of exercise training on arterial stiffness in COPD. ${ }^{36,37}$ In a small case-controlled study with 17 COPD patients, Vivodtzev et $\mathrm{al}^{36}$ showed that after 4 weeks of exercise training, arterial stiffness was reduced in the intervention group, whereas it remained unchanged in the control group. In a case-controlled study by Gale et $\mathrm{al}^{37}$ aortic stiffness was also improved after a standard multidisciplinary pulmonary rehabilitation in 32 stable COPD patients. However, further studies are needed to investigate if the independent association between arterial stiffness and PAL is also modifiable by changes in PAL.

In accordance with previous studies performed in healthy subjects and patients with COPD, age and female sex were independently associated with a higher degree of arterial stiffness, whereas BMI showed an inverse independent association. A similar inverse relationship between AI and BMI has been documented in earlier studies. ${ }^{9,38}$ However, the pathophysiological background of this association is still unclear.

The current study has some limitations. The cross-sectional study design does not allow establishing a causal relationship between arterial stiffness and PAL in patients with COPD. The cohort is mainly representative for patient care in a university hospital. Therefore, predominantly patients with more advanced stages of COPD were included.

\section{Conclusion}

In conclusion, our findings suggest that in COPD patients, a higher PAL seems to favorably influence arterial stiffness and therefore may reduce cardiovascular risk.

\section{Acknowledgment}

This study was supported by Lunge Zurich.

\section{Disclosure}

The authors report no conflicts of interest in this work.

\section{References}

1. Anthonisen NR, Connett JE, Enright PL, Manfreda J. Hospitalizations and mortality in the Lung Health Study. Am J Respir Crit Care Med. 2002;166(3):333-339.

2. McGarvey LP, John M, Anderson JA, Zvarich M, Wise RA. Ascertainment of cause-specific mortality in COPD: operations of the TORCH Clinical Endpoint Committee. Thorax. 2007;62(5):411-415.

3. Clarenbach CF, Senn O, Sievi NA, et al. Determinants of endothelial function in patients with COPD. Eur Respir J. 2013;42(5):1194-1204.

4. Rosenbaum D, Giral P, Chapman J, et al. Radial augmentation index is a surrogate marker of atherosclerotic burden in a primary prevention cohort. Atherosclerosis. 2013;231(2):436-441.
5. Lind L, Berglund L, Larsson A, Sundstrom J. Endothelial function in resistance and conduit arteries and 5-year risk of cardiovascular disease. Circulation. 2011;123(14):1545-1551.

6. Laurent S, Boutouyrie P, Asmar R, et al. Aortic stiffness is an independent predictor of all-cause and cardiovascular mortality in hypertensive patients. Hypertension. 2001;37(5):1236-1241.

7. Mattace-Raso FU, van der Cammen TJ, Hofman A, et al. Arterial stiffness and risk of coronary heart disease and stroke: the Rotterdam Study. Circulation. 2006;113(5):657-663.

8. Maclay JD, McAllister DA, Mills NL, et al. Vascular dysfunction in chronic obstructive pulmonary disease. Am J Respir Crit Care Med. 2009; 180(6):513-520.

9. Sabit R, Bolton CE, Edwards PH, et al. Arterial stiffness and osteoporosis in chronic obstructive pulmonary disease. Am J Respir Crit Care Med. 2007;175(12):1259-1265.

10. McAllister DA, Maclay JD, Mills NL, et al. Arterial stiffness is independently associated with emphysema severity in patients with chronic obstructive pulmonary disease. Am J Respir Crit Care Med. 2007; 176(12):1208-1214.

11. Vanfleteren LE, Spruit MA, Groenen MT, et al. Arterial stiffness in patients with COPD: the role of systemic inflammation and the effects of pulmonary rehabilitation. Eur Respir J. 2014;43(5):1306-1315.

12. Vivodtzev I, Tamisier R, Baguet JP, Borel JC, Levy P, Pepin JL. Arterial stiffness in COPD. Chest. 2014;145(4):861-875.

13. Shiroma EJ, Lee IM. Physical activity and cardiovascular health: lessons learned from epidemiological studies across age, gender, and race/ ethnicity. Circulation. 2010;122(7):743-752.

14. Watz H, Waschki B, Meyer T, Magnussen H. Physical activity in patients with COPD. Eur Respir J. 2009;33(2):262-272.

15. Garcia-Aymerich J, Lange P, Benet M, Schnohr P, Anto JM. Regular physical activity reduces hospital admission and mortality in chronic obstructive pulmonary disease: a population based cohort study. Thorax. 2006;61(9):772-778.

16. Anderson TJ. Arterial stiffness or endothelial dysfunction as a surrogate marker of vascular risk. Can J Cardiol. 2006;22(suppl B):72B-80B.

17. Rabe KF, Hurd S, Anzueto A, et al; Global Initiative for Chronic Obstructive Lung Disease. Global strategy for the diagnosis, management, and prevention of chronic obstructive pulmonary disease-GOLD executive summary. Am J Respir Crit Care Med. 2007;176(6):532-555.

18. Pauca AL, O'Rourke MF, Kon ND. Prospective evaluation of a method for estimating ascending aortic pressure from the radial artery pressure waveform. Hypertension. 2001;38(4):932-937.

19. Wilkinson IB, Mohammad NH, Tyrrell S, et al. Heart rate dependency of pulse pressure amplification and arterial stiffness. Am J Hypertens. 2002;15(1 pt 1):24-30.

20. Steele BG, Holt L, Belza B, Ferris S, Lakshminaryan S, Buchner DM. Quantitating physical activity in COPD using a triaxial accelerometer. Chest. 2000;117(5):1359-1367.

21. Manini TM, Everhart JE, Patel KV, et al. Daily activity energy expenditure and mortality among older adults. JAMA. 2006;296(2):171-179.

22. Van Remoortel H, Raste Y, Louvaris Z, et al; PROactive consortium. Validity of six activity monitors in chronic obstructive pulmonary disease: a comparison with indirect calorimetry. PLoS One. 2012;7(6):e39198.

23. Miller MR, Hankinson J, Brusasco V, et al; ATS/ERS Task Force. Standardisation of spirometry. Eur Respir J. 2005;26(2):319-338.

24. Wanger J, Clausen JL, Coates A, et al. Standardisation of the measurement of lung volumes. Eur Respir J. 2005;26(3):511-522.

25. Blacher J, Guerin AP, Pannier B, Marchais SJ, Safar ME, London GM. Impact of aortic stiffness on survival in end-stage renal disease. Circulation. 1999;99(18):2434-2439.

26. Mills NL, Miller JJ, Anand A, et al. Increased arterial stiffness in patients with chronic obstructive pulmonary disease: a mechanism for increased cardiovascular risk. Thorax. 2008;63(4):306-311.

27. Bhatt SP, Cole AG, Wells JM, et al. Determinants of arterial stiffness in COPD. BMC Pulm Med. 2014;14:1. 
28. Sin DD, Man SF. Why are patients with chronic obstructive pulmonary disease at increased risk of cardiovascular diseases? The potential role of systemic inflammation in chronic obstructive pulmonary disease. Circulation. 2003;107(11):1514-1519.

29. Yasmin, McEniery CM, Wallace S, Mackenzie IS, Cockcroft JR, Wilkinson IB. C-reactive protein is associated with arterial stiffness in apparently healthy individuals. Arterioscler Thromb Vascr Biol. 2004; 24(5):969-974.

30. Vestbo J, Agusti A, Wouters EF, et al; Evaluation of COPD Longitudinally to Identify Predictive Surrogate Endpoints Study Investigators. Should we view chronic obstructive pulmonary disease differently after ECLIPSE? A clinical perspective from the study team. Am J Respir Crit Care Med. 2014;189(9):1022-1030.

31. Waschki B, Kirsten A, Holz O, et al. Physical activity is the strongest predictor of all-cause mortality in patients with COPD: a prospective cohort study. Chest. 2011;140(2):331-342.

32. Vaitkevicius PV, Fleg JL, Engel JH, et al. Effects of age and aerobic capacity on arterial stiffness in healthy adults. Circulation. 1993;88(4 pt 1): 1456-1462.
33. Sugawara J, Otsuki T, Tanabe T, Hayashi K, Maeda S, Matsuda M. Physical activity duration, intensity, and arterial stiffening in postmenopausal women. Am J Hypertens. 2006;19(10):1032-1036.

34. Stickland MK, Vogan N, Petersen SR, Wong EY, Bhutani M. Physical activity and arterial stiffness in chronic obstructive pulmonary disease. Respir Physiol Neurobiol. 2013;189(1):188-194.

35. Vlachopoulos C, Aznaouridis K, O’Rourke MF, Safar ME, Baou K, Stefanadis C. Prediction of cardiovascular events and all-cause mortality with central haemodynamics: a systematic review and meta-analysis. Eur Heart J. 2010;31(15):1865-1871.

36. Vivodtzev I, Minet C, Wuyam B, et al. Significant improvement in arterial stiffness after endurance training in patients with COPD. Chest 2010;137(3):585-592.

37. Gale NS, Duckers JM, Enright S, Cockcroft JR, Shale DJ, Bolton CE. Does pulmonary rehabilitation address cardiovascular risk factors in patients with COPD? BMC Pulm Med. 2011;11:20.

38. Binder J, Bailey KR, Seward JB, et al. Aortic augmentation index is inversely associated with cardiorespiratory fitness in men without known coronary heart disease. Am J Hypertens. 2006;19(10):1019-1024.
International Journal of COPD

\section{Publish your work in this journal}

The International Journal of COPD is an international, peer-reviewed journal of therapeutics and pharmacology focusing on concise rapid reporting of clinical studies and reviews in COPD. Special focus is given to the pathophysiological processes underlying the disease, intervention programs, patient focused education, and self management protocols.

\section{Dovepress}

This journal is indexed on PubMed Central, MedLine and CAS. The manuscript management system is completely online and includes a very quick and fair peer-review system, which is all easy to use. Visit http://www.dovepress.com/testimonials.php to read real quotes from published authors.

Submit your manuscript here: http://www.dovepress.com/international-journal-of-chronic-obstructive-pulmonary-disease-journal 